\title{
Por uma teoria da comunicação no desporto de alto rendimento'
}

Vítor Serpa

https://doi.org/10.5628/rpcd.08.01.184
É com especial regozijo e orgulho que aceitei o convite do meu bom amigo Professor Jorge Olímpio Bento para vos falar neste dia tão especial para a Faculdade de Desporto do Porto.

Se há momentos em que as palavras de saudação e de reconhecimento vão muito além do simples cumprimento do dever formal, gostaria que acreditassem que este é um deles.

O Professor Olímpio Bento, além de um amigo que muito prezo, tem realizado, em conjunto com uma equipa competente e solidária, uma obra notável, que, infelizmente, os poderes públicos, mais preocupados com a pequena política deste nosso mal cuidado Páteo das Cantigas, não reparam e muito menos enaltecem.

No âmbito das relações com os países de língua portuguesa, na defesa das nossas seculares raízes culturais, em Goa e em Macau, na promoção e divulgação internacional das competências dos nossos técnicos, na luta contra velhos preconceitos da sociedade portuguesa em relação ao lugar que o desporto ocupa, de pleno direito, nas sociedades modernas, a Faculdade de Desporto do Porto tem vindo a desenvolver um trabalho admirável que deve orgulhar a sua Universidade, a cidade do Porto e o país. Digo, o que digo, neste dia solene para esta escola, não por me terem lisonjeado com o convite que me
Jornal A Bola (Director)

fizeram, mas porque há muitos anos que sigo o percurso coerente e persistente desta Faculdade e tenho o dever cívico de manifestar público reconhecimento por uma obra de valor inestimável e que se acrescenta à obra igualmente maior de uma escola que se orienta por princípios de rigor e de qualidade de ensino.

Que me desculpem a introdução um pouco mais longa, mas julgo que dificilmente teria melhor oportunidade para fazer este público e justo reconhecimento. Parto, pois, para o desenvolvimento do tema que vos trago e que vos proponho como assunto de reflexão, eventualmente imprevisto, para muitos, talvez novo, mas sobre o qual tenho vindo a dedicar atenção e estudo.

Pois bem,

Há uma frase que tem vindo a ser adoptada por alguns dos técnicos desportivos de conhecimento empírico e que lhes justifica o conforto de uma confrangedora ausência de vontade de saber: «o futebol não é, nem nunca haverá de ser uma ciência». E, de facto, não é. O futebol pode ser, apenas, uma manifestação lúdica num tempo de intervalo de obrigações e saturações da vida. Porém, o futebol, como qualquer outra modalidade desportiva, quando colocado ao nível do alto rendimento e do mundo global 
da competição, não sendo uma ciência, não resiste sem conhecimento, nem poderá sobreviver sem a intervenção decisiva das ciências na sua natureza pluridisciplinar.

Para todos os que aqui estão, homens de fé na ciência e nos saberes, este conceito, com que abrimos esta minha tão pouco natural quanto surpreendente intromissão numa casa de grandes e reconhecidos méritos universitários, não deverá causar contestação. Para todos vós será pacífico o entendimento de que o desporto e a sua prática, sobretudo se entendida ao nível das elites, só conhecerá evolução e desenvolvimento num quadro plural das mais diversas áreas científicas, todas elas específicas, mas igualmente importantes. Poder-se-á, pois, dizer, um pouco à semelhança do que sucede na área médica, ou na área a que pertenço, a da comunicação, que o técnico desportivo começa por ser, no final da sua licenciatura, um generalista do desporto. Mas se, antes, os licenciados portugueses, que o país pacóvio e mentalmente provinciano de que nos falava Pessoa logo elevava à condição de doutores, se sentiam confortáveis no que admitiam ser um ponto de chegada, hoje, com o avanço tecnológico, a investigação científica, a urgência de novas respostas para novos planos de desenvolvimento, as necessidades de conhecimento especializado tornam-se evidentes, tal como a inevitabilidade de aprofundarmos o nosso conhecimento nas áreas em que decidimos ou podemos intervir.

O licenciado em desporto, mesmo que se tenha empenhado no razoável domínio da complexa área do treino, deverá entender que, independentemente do patamar que vier a atingir, por competência, oportunidade ou simples sorte na vida, não poderá perder a consciência de que a área técnica do treino é de tal forma pluridisciplinar que, mesmo no topo de uma hierarquia, não mais terá, como acontecia há uns anos, uma função individual, isolada.

O treinador é, hoje em dia, um elemento que tem de saber trabalhar em equipa. Não podendo abarcar todas as competências necessárias à exigência cada vez maior do treino e da própria natureza complexa do atleta, deve investir, o mais possível, no conhecimento da sua área específica de intervenção e preparar-se para uma cooperação tão aberta e alargada quanto possível.
$\mathrm{Na}$ diversidade de matérias e disciplinas que a área de desporto abrange no percurso de formação universitária começa, aliás, o entendimento da visão plural do ensino e do treino desportivo. Do saber e da importância de cada uma delas entenderão vós bem mais do que eu. Por isso, se me atrevo a pisar terras que me são mais estranhas a mim do que a vós, é porque tenho vindo a reflectir, por observação de experiência acumulada de muitos anos de jornalismo e de relação directa com a área do desporto de alto rendimento, numa urgência que me parece óbvia, por dever de função, mas que não está, ainda, na ordem de prioridades do conhecimento e do saber do técnico de desporto.

Para facilidade de entendimento, pegue-se num exemplo comum de uma equipa de futebol do mais alto nível internacional. Toda a estrutura que envolve os atletas, que os acompanha, os prepara, os orienta, os estimula, os desenvolve, os conduz, tem-se tornado cada vez mais complexa e plural. Além da intervenção directa no treino, que admite a natureza específica da própria função individual do atleta, (guarda redes, defesa lateral, central, médio defensivo, médio de ataque, médio ala, ponta de lança, etc.) há a juntar a intervenção de muitas ciências diversas, da medicina à psicologia, da fisiologia à bioquímica, da estatística à biologia.

Quanto mais ricos são os clubes, mais se distinguem na qualidade e diversidade dos técnicos colocados à disposição da equipa e de cada um dos seus elementos. Daí que o chefe de uma equipa tão diversa e tão numerosa deva possuir competências muito especiais, que o capacitem para uma coordenação mais do que simplesmente intuitiva, assente numa inteligência dinâmica e interactiva.

Ora, a questão que coloco e que proponho com alguma novidade, é, precisamente, a da estranha e inexplicável incoerência de não se entender que ao mais alto nível do treino de alto rendimento, quer seja na sua vertente individual, quer seja na colectiva, se torne absolutamente essencial ao desenvolvimento inteiro do atleta e à melhoria global do seu rendimento desportivo a intervenção regular e estruturante das ciências da comunicação.

Não deixa de ser curioso que todos nós, colocados nos mais diversos sectores de actividade, aceitamos viver num mundo que fez da comunicação a sua 
relação essencial com a vida. Nada faz hoje verdadeiramente sentido, que não seja comunicável. Para ser mais drástico, a verdade é que, no mundo da comunicação, nada verdadeiramente existe quando ninguém sabe que existe.

É esta natureza, eventualmente excessiva, injusta e até cruel, mas incontornável, de um mundo que apenas se preocupa com o que sabe existir, porque ouve, ou porque vê, que não pode, ou não deve continuar a ficar de fora e, pura e simplesmente a inexistir na formação do técnico desportivo e, muito especialmente, do atleta de alto rendimento.

O desporto, ao mais alto nível, tem um mediatismo apaixonado e febril. Por isso, demasiado perigoso. É impossível, até num simples quadro de consciência das realidades, continuar a consentir que as ciências da comunicação continuem a ficar à porta do mundo do desporto. Quer seja o mundo restrito do clube, quer seja o mundo da universidade. E assim sendo, será bom que seja, então, a escola a introduzir, no âmbito de formação dos técnicos desportivos, o reconhecimento da necessidade da intervenção das ciências da comunicação aplicadas ao desporto.

Recentemente, num encontro de directores de alguns dos mais importantes jornais desportivos da Europa, o presidente do Real Madrid, que promoveu a reunião, dava-me conta de que o clube iria passar a celebrar contratos com os seus atletas profissionais de futebol, que incluiria uma cláusula de obrigações na relação com os media, procurando assim defender o clube do enorme assédio que as grandes empresas fazem aos melhores jogadores, tentando tirar partido da sua imagem e da sua capacidade de fazer chegar qualquer mensagem a um universo muito alargado de pessoas, em qualquer parte do mundo.

Muitos dos melhores atletas do Real Madrid, pagos, com muito dinheiro, para passar mensagens que favoreçam a imagem de marcas tão diversas como de roupa, relógios, perfumes, bancos, telefónicas, etc, começavam a mostrar grande relutância em falar aos jornalistas, sem compensações financeiras, passando apenas a imagem de si próprios e do seu clube. «E no entanto, essa relutância não se entende, até porque somos nós, clubes, que pagamos os seus milionários contratos» - dizia-nos, Ramón Calderón. Percebendo que o Real Madrid necessitaria de olhar para este problema, relativamente novo, com uma visão moderna e de futuro, Calderón anunciava-nos que iria contratar técnicos de comunicação obrigando os seus atletas a frequentar aulas privadas, aproveitando tempos mortos de estágio e preparando-os para enfrentarem as câmaras de televisão, os microfones das rádios e os jornalistas da imprensa escrita, ganhando novos conhecimentos de técnicas de expressão, que os levaria a saber como passar as mensagens essenciais à sua própria imagem e à imagem do clube que contratara os seus direitos desportivos.

E, mais do que isso. O estudo feito pelo Real Madrid dava conta de que ao melhorar a qualidade e a capacidade de comunicação dos seus técnicos e, especialmente, dos seus atletas, seria previsível que melhorasse o rendimento desportivo da equipa. «O estudo aponta para esta realidade: quanto mais à vontade estiverem os atletas e os técnicos para enfrentar a pressão mediática a que um clube como o nosso naturalmente está sujeito, mais condições tem a equipa de resolver bem a pressão que o adversário e o público a submete no jogo» - garantia-nos o presidente do Real Madrid.

No entanto, as grandes estrelas da equipa não se sentiam sensibilizadas para participarem numa formação de técnicas de comunicação. A maioria considerava que na fase de projecção internacional em que se encontravam, os órgãos de comunicação beneficiavam mais do que eles próprios de uma entrevista, que certamente iria ter fortes repercussões na venda de jornais, ou nas audiências de televisão, sem que eles usufruíssem suficientes contrapartidas.

Nenhum deles, com excepção de Van Nistelrooy, considerava, sequer, a ideia de poder tirar dessa exposição mediática, vantagens estratégicas para a equipa ou vantagens patrimoniais para o clube. Há uma visão individualista de interesses. Pensar no interesse da equipa, só mesmo dentro do campo. Calderón admitia que perante esta realidade e não querendo afrontar as principais estrelas da equipa, decidiu apresentar os novos contratos, com cláusulas de exigência de hábitos regulares de comunicação com os media, apenas aos novos atletas do clube. Curiosamente, ou talvez não, num encontro de carácter profissional que tive com José Mourinho, em Londres, o técnico português com maior prestí- 
gio no mundo do futebol dizia-nos que afastar os jogadores da pressão dos media, como acontece em Portugal, constituía um erro grave, porque impedia, ou, pelo menos, atrasava, uma melhor formação do carácter profissional do atleta. «A decisão correcta dizia-me Mourinho - é preparar o jogador para saber como enfrentar essa pressão, tornando-o capaz de impor o discurso conveniente e de saber passar a mensagem útil, a ele próprio e ao grupo».

A novidade que o grande clube de Espanha procurava impor, apesar das dificuldades, era, apesar de tudo, uma novidade relativa, porque apenas inovadora na Europa. Há muito que, nos Estados Unidos, algumas empresas especificamente vocacionadas para técnicas de comunicação desportiva se instalaram na vida e nos hábitos dos melhores e mais mediáticos atletas americanos. A NBA tem, ela própria, uma central organizada de comunicação, que não apenas ajuda os seus membros, mas ainda tem uma acção decisiva na influência directa sobre os media que acompanham regularmente a grande prova do basquetebol norte-americano.

Os principais campeões olímpicos, especialmente na natação, no atletismo e na ginástica, também contam com formadores especializados na área da comunicação e da imagem, que lhes permite garantir vantagens decisivas, enquanto atletas, sobretudo no acesso à sponsorização, e, mais tarde, depois de terminadas as suas carreiras, como comunicadores em universidades e convenções, o que lhes permite continuar a ter reconhecimento nacional e uma mais valia financeira, que está longe de ser subestimável.

Entre as técnicas de comunicação mais usuais, estão os comportamentos na relação directa com os jornalistas e com as câmaras, quando se trata de televisão. Os atletas aprendem a não se deixarem dominar nas entrevistas, impondo os caminhos que melhor servem os seus interesses de comunicação, passam a saber como passar ao público as mensagens essenciais, como driblar as questões difíceis ou até indesejáveis, ganham desenvoltura na comunicação, tornam-se experientes na expressão e nos olhares, aprendem a dar, de si próprios, uma imagem de segurança e de estabilidade psicológica, dominando as situações.

Em face disto, percebe-se que, em Portugal, se assiste, ainda, a um tempo primitivo do homem desporti- vo, aliás, ainda um tanto troglodita, sobretudo nas áreas em que a pressão mediática é maior, como é o caso do futebol. A relação entre os principais clubes profissionais e os media, em especial, a imprensa desportiva, é dramaticamente amadora. Em cada dia, assiste-se, da parte dos intervenientes directos, especialmente atletas, a uma comunicação primária, desinteressante e, não raras vezes, desmobilizadora de público. Num sector da vida desportiva, onde se tomam naturais cuidados de rigor e de profissionalismo, a área da comunicação, talvez uma das áreas mais importantes no mundo mágico do espectáculo desportivo, é votada ao mais surreal amadorismo. Quem fala, ainda julga que fala para jornais, no sentido literal do termo, e não percebe que fala para o mundo. A partir deste equívoco, quem ainda se dá a tão desinteressante trabalho de comunicar, raramente tem uma ideia sobre o que deve comunicar, que imagem deve fazer passar para o exterior, que mensagem se tornará útil a si próprio e à sua equipa. Em nome do falso interesse do grupo, os futebolistas profissionais portugueses são transportados para um mundo irreal, fechados num género de castelos doirados numa desastrada tentativa de os defender contra os perigos do mundo exterior.

Em resultado disso, o futebolista-tipo português perde autonomia, não gera um carácter forte no relacionamento com os outros, consolida uma personalidade imatura que, não raras vezes, se reflecte nas atitudes e nas pobres declarações públicas que presta à comunicação social. Não é mentalmente sólido e apenas se sente seguro quando se julga protegido por dirigentes paternalistas, ou no interior do seu grupo. Não se sentindo capazes de se relacionarem com a pressão que a sociedade inevitavelmente lhes impõe, a sua identidade desvanece-se na conclusão errada de que, fora do seu grupo, apenas existe um mundo agressor que o ameaça e o prejudica. Percebe-se, assim, porque técnicos e jogadores tanto se sustentam de lugares comuns. Sucedem-se conferências de imprensa em que é difícil ir além do «temos de salir a ganar» de Camacho, que também trouxe de Espanha a maior invenção do século: «se marcarmos mais golos, que o adversário, ganhamos». Com tais exemplos, os atletas também se desmobilizam e não sentem como é insensato perder a oportunidade de aproveitamento do tempo e do espaço de comuni- 
cação com o exterior. Por isso, repetem-se frases feitas de há muitos e muitos anos, que os jornalistas acabam por reinventar numa esforçada missão de vender o que já há muito tempo foi mal comprado. Nesse mundo pouco consequente do futebol, ninguém, ou quase ninguém, tem suficiente sensibilidade para entender a verdadeira dimensão da importância de comunicar, sabendo o que se comunica, como se comunica e a quem se comunica.

Como é óbvio, a culpa não pode ser assacada a quem faz da comunicação essa rotina desinteressante, vulgarzinha e até mesmo penalizadora. Há que ganhar, primeiro, a consciência dessa importância a um nível superior de conhecimento e não vejo melhor do que a oportunidade das universidades estudarem e investigarem no sentido de unir a omnipresente realidade da comunicação nas sociedades modernas, com o reconhecimento da importância de intervenção das ciências da comunicação aplicadas à área do desenvolvimento do desporto de alto rendimento. E tanto ou mais importante do que preparar um atleta a saber expressar-se, será ensiná-lo a saber usar e trabalhar a sua imagem. Tal como nos diz Doris Graeber, um americano universalmente respeitado nas ciências da comunicação e que também passou pelas ciências políticas e da economia, a «mensagem verbal é muito importante, mas a imagem é determinante». A razão é explicada por ciências como a neurobiologia, que nos dá conta de que a linguagem verbal e a linguagem visual são processadas em diferentes zonas do cérebro, sendo que esta última é mais directa e representa, por isso, a nossa forma principal de aprendizagem.

Damos facilmente conta da importância da imagem na comunicação nos noticiários televisivos, onde a sensação de segurança, credibilidade e respeitabilidade do pivot se torna bem mais importante e decisiva para as audiências, do que a notícia. Se um leitor de jornais se fideliza pela afectividade ao seu jornal, que não quer ver demasiado mudado, um espectador de informação na televisão, fideliza-se pelo seu pivot preferido.

Recorrendo ainda a Doris Graeber, e agora que entrámos numa fase decisiva do período eleitoral para a presidência dos Estados Unidos, talvez o maior e mais expressivo palco de comunicação universal de que há conhecimento, lembremos o que ele nos disse: «Não sei se, hoje, Abraham Lincoln teria sido eleito ou, mesmo, Franklin Roosvelt, que foi tão popular, mas tinha o corpo deformado devido à poliomielite».

A tese que perante vós, convicta e apaixonadamente defendo é, pois, a de que as ciências da comunicação devem passar a fazer parte do mundo pluridisciplinar do treino desportivo, entendendo o treino numa perspectiva global de preparação e desenvolvimento de capacidades para o exercício da função do mais elevado rendimento desportivo.

E, nesta escola, que tantas vezes tem sido pioneira na interacção entre o saber e a sua prática, fará todo o sentido que, em tempo útil, se entenda relevante criar um departamento da comunicação, capaz de garantir ensinamentos específicos para melhor preparação dos técnicos desportivos, mas também apta a dar apoio directo a clubes e atletas de elite, como já acontece, por exemplo, em áreas como a da psicologia, garantindo meios essenciais de apoio a uma área do desporto que permanece totalmente desprotegida e estranhamente desqualificada.

Não se trata, sequer, conforme procurei demonstrar, de uma visão meramente futurista de um desporto que apenas se supõe poder vir a existir. O que se vê e facilmente se entende é que a maioria dos atletas de alto rendimento, quer na expressão individual, quer colectiva, a par de técnicos, mesmo aqueles que têm uma correcta noção pluridisciplinar da sua função, lidam mal com a pressão mediática, aproveitam mal o espaço e o tempo que se lhes oferece para comunicarem com o mundo, não conseguem fazer passar uma imagem positiva de si próprios e das entidades desportivas que servem. $\mathrm{E}$, mesmo quando atingem grandes títulos e marcas internacionais, raramente têm consciência de como poderão vir a aproveitar o reconhecimento dos seus feitos e a consagração das suas carreiras numa acção que se prolongue no tempo, continue a garantir naturais benefícios financeiros e contribua, de forma sustentada, para a promoção e desenvolvimento do desporto. Não gostaria muito de dar exemplos individuais comparados que poderão ser mal entendidos por alguns dos nossos maiores atletas olímpicos, mas não será excessivo considerar que a capacidade de comunicação de Nuno Delgado não apenas o ajudou, pessoalmente, a notabilizar-se, depois da medalha de Sidney, como ajudou ao desenvolvimento mais rápi- 
do do judo. Exemplo não menos notável é o de Rosa Mota, que sempre manteve um nível superior de comunicabilidade com o mundo exterior que faz dela, ainda hoje, um dos maiores ídolos populares do desporto português.

Talvez ainda valha a pena recorrer ao exemplo eventualmente excessivo, mas, até por isso, significativo, do râguebi. Nunca, como no último mundial de França, se terá mascarado tão bem uma derrota (para mais tão volumosa) como a que a selecção portuguesa de râguebi sofreu no encontro com a Nova Zelândia. Apesar de ter sofrido mais de cem pontos, os seleccionados foram elevados à condição de heróis, pelo vigor com que jogaram, sim, mas, acima de tudo, pelo vigor com que cantaram o hino. A verdade é que as televisões pegaram na história, percebendo que era facilmente vendável, e o râguebi, que teve apenas derrotas desportivas, chegou a Portugal em cenário de glória nacional e, nos meses seguintes, o aumento jovens raguebistas aumentou de tal forma que a maioria dos clubes não tinha condições estruturais para os receber.

Acredito, sinceramente, que esta proposta de inclusão das ciências de comunicação, adaptada ao ensino dos técnicos de desporto e às exigências do desporto de alto rendimento, deverá ser suficientemente avaliada e admitida como projecto realizável e útil. E deve ser incluída, tão depressa, quanto possível, nas áreas de investigação e estudo da universidade.

Meus generosos e pacientes ouvintes, agradeço-lhes a atenção que me dispensaram, mais do que a mim, a esta tese em que me revejo. O mundo da comunicação é importante de mais para apenas fazer parte do universo dos media, ou para servir de simples arte de manipulação de massas, por parte de políticos mal formados. As ciências da comunicação, aplicadas ao desporto, poderão trazer-nos, estou convicto disso, técnicos mais competentes e atletas de personalidade mais sólida e, por isso, melhor preparados para enfrentarem as difíceis exigências da competição ao mais alto nível e a forte pressão que as sociedades modernas exercem sobre os seus heróis. As técnicas de comunicação podem eleger presidentes, podem tornar justas guerras cruéis, podem manter ditadores eternamente no poder, podem, até, mudar a verdade da História. É, por isso, uma arma perigosa e não raras vezes decisiva nos tempos que correm. O que vos proponho, aqui, nesta sessão solene de uma escola que sempre soube abraçar o futuro como um desafio estimulante, é que as aproveitemos para fins bem mais benignos, respondendo melhor e com mais conhecimento às sempre novas exigências que as sociedades modernas impõem ao desporto e aos atletas de alto rendimento.

\footnotetext{
${ }^{1}$ Comunicação proferida na sessão solene de atribuição de prémios e diplomas aos melhores estudantes da Faculdade de Desporto da Universidade Porto (Março de 2008)
} 